\title{
Representation of the Equal Relationship in the Development of Mathematical Thinking: A Case of Grade One's
}

\section{Zingiswa Mybert Monica Jojo}

University of South Africa

jojozmm@unisa.ac.za

\section{Doi:10.5901/mjss.2014.v5n23p914}

\begin{abstract}
This paper presents a practical demonstration and presentation observed whilst a pre-service teacher was teaching a mathematics lesson on 'doubling a number'(Ukuphinda kabili)', 'to thirty two grade one learners in a primary school in kwaZulu Natal of South Africa. The lesson was presented in Zulu, the learners' home language in line with the Curriculum Assessment Policy Statement (CAPS) which requires all phase one (grade 1-3) learners to be taught mathematics and other subjects except English in their vernacular in South African public schools. The lesson engaged learners in games and interactions involving replicating a given number twice using stones or bottle tops, combining them and then counting and registering their total. The symbolic representations though and the use of equal sign were misleading on the chalkboard. Interviews with the teacher after the lesson revealed that the teacher assigned no particular meaning to the equal sign used in the number sentences. Also the teacher revealed that he was aware that at grade one level the multiplication sign could not be used and did not know how to represent a duplicate of a value without a sign so as to get double the number.
\end{abstract}

Keywords: doubling, equal sign, contrast, separation, generalisation, fusion.

\section{Introduction}

Learners need language in order to develop mathematical concepts. Language development is always important in the use of numeracy, particularly mathematical language. This can be justified by the inclusion of the basic concepts of colour, shape, size and others associated with mathematics in the 'Thinking and Reasoning' of the Language Learning Area. Numeracy is "... the ability to process, communicate and interpret numerical information in a variety of contexts (Askew, Brown, Rhodes, Williams, \& Johnson, 1997:25). This implies that numeracy intersects with number sense, a concept that incorporates both understanding and using mathematics. Howden (1989:11) describes number sense as 'as a good intuition about numbers and their relationships. It develops gradually as a result of exploring numbers, visualising them in a variety of contexts, and relating them in ways not limited by traditional algorithms. Number sense is vital for learners to use when building up an understanding of computational strategies. The challenge is that number sense cannot be taught to learners but they acquire it by being exposed to various activities that allow them to construct knowledge for themselves.

Very often learners in grade one, are taught to count and to know 'facts off by heart' such that they can recite them. It is in this grade where a foundation for development of mathematics has to be built. This suggests that some groundwork upon which students can reflect as the basic ideas found in mathematics has to be laid and utilised so that it can be developed in latter grades. Reciting informs recalling with thorough practice but cannot guarantee that the learners understand any of the concepts, what they are doing, or that they will be able to use these facts in different contexts. Teachers need to design activities aimed at helping learners to develop a sense of number. Researchers, Greeno (1991), Reys (1991), and Sowder and Schappelle (1994) extend the meaning of number sense to include well understood number meanings, well developed multiple relationships among number, a level of "comfort", a "friendliness" with numbers, a relating of number to one's own experiences from which number relationships are readily perceived, and knowing the relative effect of operating on numbers. This, Howden (1989) describes as an exploration and interpretation of number beyond algorithmic contexts as an element of number sense. Often teachers need to ask and encourage the learners to reflect on what they are doing and afford them a chance to talk about it to enhance the development a sense of number.

Pre-service teachers are always encouraged to keep learners active and mentally engaged in the mathematics lessons. Constructivists argue that all learners use the ideas they currently have to form or create new ones. Constructivism is not a way of teaching but rather it is a theory about how the human mind learns. Children must be 
mentally active for learning to take place. In the classroom I observed, grade one learners were provided with opportunities to construct their own knowledge during processes of articulating, defending, evaluating, and reflecting upon their understandings and shared practices on doubling a number. The actions involved picking a certain number of items, repeating the action with the same number of items, combining them and then counting how many items one had altogether. Pictorial and symbol illustrations on the chalkboard only followed the practical part at a later stage respectively.

\section{Literature Review}

Essien (2009) argues that the equal sign should first be introduced using appropriate pictorial representations and artefacts before the introduction of the plus and minus signs. This was the strategy used meticulously by the teacher observed. Various artefacts in the form of stones, bottle corks, buttons and match sticks were used in action whilst the learners observed first how a number of objects can be replicated in number and then added and counted together by all learners. These were followed by pictorial representations on the chalkboard indicating 'ukuphinda kabili' as in the pictorialin Fig 1. In the caps document of the English version, this topic appears as 'adding doubles'. Thus the operation is clearly addition of the same number twice. The Zulu version instructs the learners to 'repeat (phinda) twice (kabili) whatever action the learners was doing. The controversy could be that it is obvious that after addition, the learners need to count the combination of the doubles and give an answer. When giving the number of objects in the combination, the learner has to internalise the equal sign as a relational object. Repeating twice has to stress a combination of addition which would then be equal to a double. This understanding is not obvious for a grade one learner, it has to be taught. This was reiterated when Esseien (2009) suggested that knowledge on how to organise the learners' first encounter with a particular concept is crucial to the type of internalisation that occurs in the learners.

Various researchers (Behr, Erlwanger, \& Nichols, 1980; Carpenter, Franke, \& Levi, 2003; Demonty \& Vlassis, 1999; Essien \& Setati, 2006; Falkner, Levi, \& Carpenter, 1999; Kieran, 1981; Knuth, Stephens, McNeil, \& Alibali, 2006) and others have long recognised that learners tend to misunderstand the equal sign as an operator, or as a symbol inviting them to "do something", to "find the answer", rather than as a relational symbol signifying equivalence or quantitative sameness. Rather many learners at primary and early secondary levels understood the equal sign as either a do-something symbol that automatically invite them to write the answer and/or a unidirectional symbol. Essien (2009) though argues for the equal sign to be given the same status and attention as the addition and subtraction signs both in the textbooks and the curriculum. The Principles and Standards also notes that the common learners' understanding of the equal sign at this stage (foundation phase) should be more accurate than the limited understanding of the equal sign as signifying "the answer is coming". Learners need to understand that the equal sign "indicates a relationship that the quantities on each side are equivalent" (NCTM, 2000, p. 94). The CAPS document fails to stress the use and understanding of equal sign as was with the previous curricula, Outcomes Base Education (OBE) and Revised National Curriculum Statement (RNCS) in South Africa. The CAPS seems to take for granted the fact that the equal sign, (unlike the plus sign or minus sign), needs to be highlighted explicitly in texts and pedagogy in order for learners to develop a more sophisticated understanding of the equal sign (DOE ;2011).

McNeil, Rittle-Johnson, Hattikudur, and Petersen (2010) assert that as children develop, many come to a relational conception of the equals sign as indicating numerical sameness, and are accepting of a wider variety of equation types. However, this happens to varying extents and even those that develop a sophisticated understanding of the equals sign readily revert to operational views (seen as a do something signal) of symbolic mathematics. They further presented evidence that in addition to the operational and relational conceptions of the equal sign, there is a distinctive substitutive conception. The substitutive conception of the equal sign is another level where learners need to understand that the two sides in an equation or a number sentence can be replaced by each other since they are equal. They then classified the following meanings on understanding equal signs. 
Table 1: Equals signs definitions presented

\begin{tabular}{|c|l|l|}
\hline The equals sign means... & Conception & Relational \\
\hline R1 & the two amounts are the same & Relational \\
\hline R2 & that something is equal to another thing & Relational \\
\hline R3 & that both sides have the same value & Operational \\
\hline O1 & the total & Operational \\
\hline O2 & work out the result & Operational \\
\hline O3 & the answer to the problem & Substitutive \\
\hline S1 & the two sides can be exchanged & Substitutive \\
\hline S2 & the right-side can be swapped for the left-side & Substitutive \\
\hline S3 & that one side can replace the other & \\
\hline
\end{tabular}

Haylock (2008) asserts that the essence of the problem with the equal sign is that the concept of equals is such a complex network of ideas and experiences. He further notes that there is not just one form of words that goes with the symbol ( $=$ ) but that there is a range of language and situations to which the symbol may become attached, including both the ideas of transformation and equivalence. It is a symbol which most teachers articulate their anxieties about its meaning. Haylock emphasises that the phrase 'is the same as' is particularly significant as the underlying equivalence in statements in arithmetic that use the equals sign.

When the child puts out two sets of three bottle corks, forms their union and counts the new set to discover that there is now a set of six bottle corks, it is a bit obscure to suggest that this is an experience of 'two sets of three, is the same as six'. The child has actually transformed the two sets of three into a set of six. The child's attention therefore is focused on the transformation that has taken place. This being so, it seems perfectly natural, and surely appropriate, to use the language 'two three's make six' to describe the transformation the child has done. One of the teachers quoted above said that she regarded the symbols as instructions to do something. In other words, the equals sign tells you to apply some sort of transformation. Thus in practice, the equal sign represents equivalence and transformation.

\section{Theoretical Framework}

The equal sign meanings described above will be analysed using the variation theory in this article. Leung (2012) is of the opinion that teaching and learning of mathematics is about providing learners opportunities to experience mathematics and to create (new) mathematical experiences. He further argues that although memorizing a formula, executing an algorithm, writing a down a string of mathematical symbols, proving a proposition, or recognizing a pattern, are all related to mathematics they are critical enough to ensure the occurrence of a genuine mathematical experience. There needs to be a connection between the learner and the 'object of learning' in mathematics. This involves pedagogy and use of tools or manipulatives that become potential mediators for mathematical experience (Maschietto \& Trouche, 2010). To this Leung (2010) describes mathematical experience as "the discernment of invariant pattern concerning numbers and/or shapes and the re-production or re-presentation of that pattern." He therefore proposed the variation theory where he defined variation as what changes, what stays constant and what the underlying rule is, in any phenomenon.

Variation is defined by its critical features that must be discerned in order to constitute the meaning aimed for in a lesson (Marton \& Tsui, 2004). The teacher then has to decide on a pedagogic approach that accommodates a pattern of variation as a useful tool in structuring teaching to help the learners to construct relevant mental constructs for the concept to be learnt or object of learning. Marton (2009) proposed four kinds of awareness brought about by different patterns of variation. These include:

- Contrast presupposes that for one to know what a concept is, he/she has to discern and know what it is not, (Leung, 2012). Ling (2012) observed that teachers have a tendency of putting emphasis on what a concept is (examples), instead of what it is not or how the concept differs from related ones (non-examples).

- Separation assumes that all concepts have a multitude of features, each of which give rise to different understandings of the concept. For example doubling a number is the same as adding the same number twice or just twice the number. Ling (2012) therefore suggests that it is necessary for teachers to consider learning as a function of how learners' attention is selectively drawn to the critical aspects of the concept. He is of the view that certain aspects of the concept should be varied while others are kept constant to help learners to discern new aspects of the concept and construct new meanings that might have not been apparent before.

- Generalisation according to Leung and Chik \& Marton (2012) refers to the verification and conjecture making 
activity that checks out the validity of a separation. Variation of separation and generalisation of features of a concept are sometimes not distinct from each other.

- Fusion is the simultaneous discernment of all the critical features of a concept and a relationship between them which allows a learner to make connections gained in past and present interactions. For more elaborations on the variation theory see Mhlolo (2013, p11). The diagram below gives a summary of the variation theory.

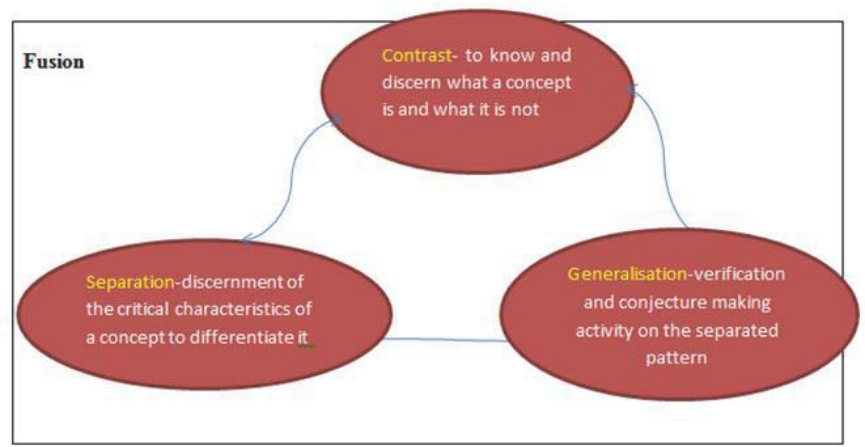

Fig 2: The four kinds of variation theory interactions

\section{Methodology}

The study followed an exploratory design where data was collected through observations of the pre-service teacher presenting a mathematics lesson to a grade one class of thirty two learners. The school was a no-fee school, underresourced and in an impoverished rural setting. The observations in class were followed by interviews with the teacher to get clarity on the pedagogy dynamics used in class and later some three learners on their understanding on the lesson. The exploratory design was used to determine the understanding displayed by the learners regarding number sense with respect to the constructivists view. The study also explored the views and roles of the teacher, learners and the challenges learners had in understanding 'ukuphinda kabili'.

This was a qualitative study where 32 grade one learners were divided into eight groups of four and were presented with learning aids like bottle corks, stones, ten 2 square $\mathrm{cm}^{2}$ colorful paper strips and match sticks. Two of the eight groups had similar items. Instructions started with a racing game. There were four games and each learner was the leader of a particular game. The groups were numbered one up to eight with colorful stickers. The instructions were clear and were orally given to the learners in their mother tongue. They were to pick a certain number of items, isolate them from the group and then had to repeat the action once more. This the teacher referred to as 'ukuphinda kabili'. A group would get a score by counting the total number of items combined and giving a correct response. The second exercise involved a diagrammatic representation of the 'ukuphinda kabili' by the teacher on the chalkboard. Lastly the teacher represented the processes using numerical symbols on the chalkboard.

\section{Analysis}

The game phase aroused much interest to the learners. They enjoyed the game. They understood the instructions with ease since they were presented in their mother tongue. The teacher also demonstrated physically for each group the nature of the exercise. She isolated two items, repeated the action, combined the first two objects with the other ones. She then counted out the combined group of items to get a four. She also explained in vernacular that 'Uma uphinda izinto ezimbili kabili, ufumana ezine (When doubling two items twice, we get four). Learners were provided with opportunities to construct, interpret and, acquire mathematical knowledge in communication with their peers in their different groups. The learners were also active, worked collaboratively in groups, and engaged in negotiation and consensus building on the meaning of mathematical ideas using number sense. This matches nicely with what doing mathematics is about, for a major aim of mathematical activity is to separate out invariant patterns while different mathematical entities are varying, and subsequently to generalize, classify, categorize, symbolize, axiomatize and operationalize these patterns. Contrast was not used in this exercise since learners were not exposed to non-examples in this exercise. Terms like even and odd were also not built in or mentioned in this exercise. 
The exercise above was operational and was successful in making the learners to understand the doubling process at the concrete stage. Learners were for example asked to put one bottle cork next to another and to count and say how many there are altogether. The teacher instructed learners to place an item on the desk, and then place another one next to it and to ask the learners how many items there are altogether. The idea was to show, for example, that "three and three makes six" and to show the learners that this process is called doubling, (phinda kabili'). This was then followed by the pictorial representations of items to be doubled, and the illustrations were drawn by the teacher on the chalkboard (see fig 1).

Figure 1: Illustration of three repeated twice

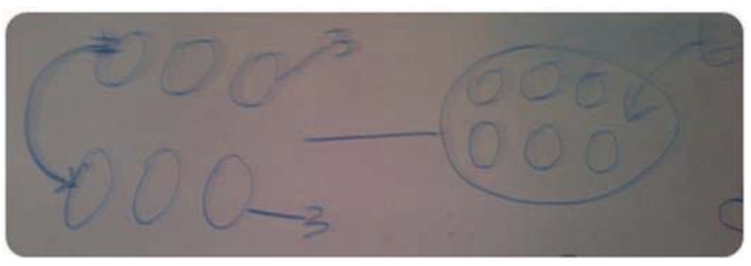

These pictorial diagrams aimed at enabling learners see and understand the significance of the equal sign in the doubling process. Here the equal sign was operational and relational serving level of $\mathrm{O} 3$ and $\mathrm{R} 3$ respectively. The equal sign was not represented as a symbol on the diagrammatic picture, but rather as an arrow. There was also an elaborate explanation on activities around doubling and the outcomes after doubling. Activities included the counting of the items in a figure, recording and counting items after combination in a bigger figure.

\section{Results}

In this lesson observed, contrasting examples were suggested so that learners could see the non-examples. For example, they were cautioned that if you have five items, one needs to bring the same number of items to double them. 'Uma uphinda izinto ezintathu, ngekhe uze ne zimbili' (When doubling three items, you cannot bring two items. 'Kuzoshoda enye' (you will be one short). Contrasting issue here was for example when one brings three bottle corks and three match sticks, does this mean that 'siphinda kabili' (are we doubling the number or must it be the same items always)?. Although the teacher demonstrated the doubling process, he failed to lead the learners to generalisation and thus fusion could not take place. Emphasis was just on repetition of the doubling of numbers. This is supported by Marton, Wen and Wong (2005) who pointed out that the likelihood of being able to recall something is higher if the learners hear or see something several times than if they do not. Nonetheless the activities were not aimed at explicitly entrenching in learners the significance of the equal sign.

The teacher's generalisation and consolidation of the lesson were misleading. From the pictorial representations on the chalkboard, the concept of the equal sign (as signifying an equivalent relation) was mis-represented by the teacher when using symbols. He introduced the equal sign, without explicitly putting meaning to it. This representation of the equal sign as "the same as" or "makes" or 'is equal to' just conceived the equal sign as simply a tool for writing the answer. It did not play the role in relating the quantitative sameness between objects on the left-hand-side and objects on the right-hand-side. Essien (2001) notes the importance of the equal sign in mathematics as one of the most used signs and notations in mathematics, but reckons that the equal sign is a symbol that is very easily misunderstood by learners. He therefore argued that the equal sign needs to be accorded the same status as the plus and minus signs in the curriculum.

Although Essien (2001) encourages the use of pictorial representation of objects familiar to the context of learners of that age bracket to introduce the concept of the equal sign. He further cautions teachers to avoid using the equal sign between two objects (e.g., a door $=$ a rectangle) as this does not represent a relationship of equality between numbers and therefore, does not focus on the significance of the equal sign. This the researcher witnessed during observation when the teacher made a symbol representation of the exercises performed practically and pictorially on the chalkboard.

'Ake sibhale ke manje konke loku esikade sikwenza ngamanani ebhodini (Let us now write all that we have been doing on the chalkboard in numbers on the chalkboard.). The captured picture in Figure 3 represents the four problems given by the teacher for learners to give answers to the outcome after doubling a number. One of the questions asked by the learners was whether they needed to double the sequential $1 ; 2 ; 3$; and 4 or finish up the sentence after the equal sign? This in itself was much confusing for the grade one's even though their 'equal sign' concept lacked construction of 
meaning. The teacher made some false illustrations as examples to be followed by the learners in completing the sentences. She completed the first one as $4=8$ and instructed the learners to follow suit with the others.

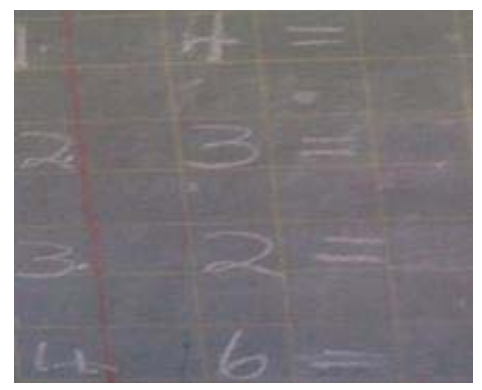

Fig 3: Teacher's illustration on the chalkboard



Fig 4: Learners' work marked

The above representations are delusional. The teacher has attached no meaning to the equal sign. It was neither operational, nor relational. It was also not important that one side can replace the other or that both sides have the same value. The teacher focussed only on the fact that the learners are able to double the given number. In this way, the learners were not given a chance to contrast to know and discern what doubling is and what it is not. In terms of action and diagrammatic representations, they were able to separate and discern the critical characteristics of a doubling and could differentiate it from a single action. The misleading symbolical representation where the equal sign is used to instruct 'double' uprooted any other true meaning that could be assigned to this symbol. Interviews conducted with the teacher indicated that she didn't know how to represent doubling using a mathematical symbol since the grade one South African syllabus did not allow children at that stage to be introduced to multiplication by two or use of any multiplication sign for that matter. She also indicated that the textbook they used also registered this error. Doing mathematics and writing it in this lesson were two separate entities and even though the teacher had assisted the learners to do mathematics, he could not help them to write it.

\section{References}

Askew, M., Brown, M., Rhodes, V., William, D., \& Johnson, D. (1997). Effective teachers of numeracy in UK primary schools: Teachers' beliefs, practices and pupils' learning. In E.

Pehkonen (Ed.), Proceedings of the 21st annual conference of the International Group for the Psychology of Mathematics Education (Vol 2, pp. 25-32). Lahti, Finland: PME Program Committee.

Behr, M., Erlwanger, S., \& Nichols E. (1980). How children view the equals sign. Mathematics Teaching, 92, 13-15.

Carpenter, T.; Franke, M., \& Levi, L. (2003). Thinking mathematically: Integrating arithmetic and algebra in elementary school. Portsmouth: Heinemann.

Demonty, I. \& Vlassis J. (1999). Les représentations pré-algebraiques de élèves sortant de l'enseignment primaire. Informations Pédagogiques, 47, 16-27.

DoE (Department of Education). (2011). Language policy for higher education. Pretoria: Department of Education.

Essien, A. (2001). One Teacher's Dilemma in Mediating Translation From Written to Symbolic Form in a Multilingual Algebra Classroom. US-China Education Review B 4 (2011) 475-481.

Essien, A.A. (2009). An Analysis of the Introduction of the Equal Sign in Three Grade 1 Textbooks. Marang Centre for Maths and Science Education. University of the Witwatersrand

Essien, A., \& Setati, M. (2006). Revisiting the equal sign: Some Grade 8 and 9 learners' interpretations. African Journal of Research in Science, Mathematics and Technology Education, 10(1), 47-58. 
Falkner, K., Levi, L., \& Carpenter, T. (1999). Children's understanding of equality: A foundation for algebra. Teaching Children Mathematics, 6, 232-236.

Greeno, J. (1991). Number sense as situated knowing in a conceptual domain. Journal for Research in Mathematics Education, 22(3), 170-218.

Howden, H. (1989). Teaching number sense. Arithmetic Teacher, 36(6), 6-11.

Kieran, C. (1981). Concepts associated with the equality symbol. Educational studies in Mathematics, 12, 317- 326.

Knuth, E., Stephens, A., McNeil, N., \& Alibali, M. (2006). Does understanding the equal sign matter? Evidence from solving equations. Journal for Research in Mathematics Education, 37(4), 297-312.

Leung, A. (2010). Empowering learning with rich mathematical experience: reflections on a primary lesson on area and perimeter, International Journal for Mathematics Teaching and Learning [e-Journal]. Retrieved April 1, 2010, from http://www.cimt. plymouth.ac.uk/journal/leung.pdf

Leung, A. (2012). Variation and mathematics pedagogy. In J. Dindyal, L.P. Cheng, \& S.F.

$\mathrm{Ng}$ (Eds.), Proceedings of the 35th Annual Conference of the Mathematics Education Research Group of Australasia (pp. 433-440). Singapore: MERGA. Available from http://www.merga.net.au/documents/Leung_2012_MERGA_35.pdf

Marton, F. (2009, December). Sameness and difference in learning. Paper presented the Swedish Research Links Symposium on Phenomenography and Variation Theory, University of Hong Kong, Hong Kong.

Marton, F., \& Tsui, A. B. M. (2004). Classroom discourse and the space of learning. New Jersey: Lawrence Erlbaum.

Marton, F., Wen, Q., \& Wong, K. (2005). Read a hundred times and the meaning will appear changes in Chinese university students' view of the temporal structure of learning. Higher Education, 19, 291-318.

Maschietto, M. \& Trouche, L. (2010). Mathematics learning and tools from theoretical, historical and practical points of view: the productive notion of mathematics laboratories. ZDM - The International Journal on Mathematics Education, 42, 33-47.

McNeil, N. M., B. Rittle-Johnson, S. Hattikudur and L.A. Petersen. 2010. Continuity in Representation Between Children and Adults: Arithmetic Knowledge Hinders Undergraduates' Algebraic Problem Solving. Journal of Cognition and Development, 11, $437-457$.

Mhlolo, M. (2013). The merits of teaching mathematics with variation. Pythagoras, 34(2), Art. \#233, 8 pages. http://dx.doi.org/10.4102/ pythagoras.v34i2.233

NCTM (2000). Principles and Standards for School Mathematics. Reston, VA: National Council of Teachers of Mathematics.

Reys, B. (1991). Number sense: Building on student's intuitive knowledge. In C. J. Irons (Ed.), Challenging children to think when they compute: Developing number sense, mental computation and computational estimation, Proceedings of the 1st annual conference on Mathematics Teaching and Learning presented by The Centre for Mathematics and Promoting Mathematical Understanding: Number Sense in Action 149

Science Education, Queensland University of Technology, Brisbane.

Sowder, J., \& Schappelle, B. (1994). Number sense making. Arithmetic Teacher, 41(6), 342-345. 